\title{
Dynamics of a Market Share Model for Enterprises with Coopetition Strategy
}

\author{
Mingxia Zhao \\ Shanxi University, Taiyuan, Shanxi 030006, China \\ Correspondence should be addressed to Mingxia Zhao; zhaomxshanxi@163.com
}

Received 12 September 2013; Accepted 5 October 2013

Academic Editor: Zhen Jin

Copyright ( 2013 Mingxia Zhao. This is an open access article distributed under the Creative Commons Attribution License, which permits unrestricted use, distribution, and reproduction in any medium, provided the original work is properly cited.

\begin{abstract}
A deterministic model is used to study the change of the market share with coopetition strategy for enterprises. The model takes into consideration both coopetition enterprises and other enterprises, and the coopetition threshold $R_{0}$ is identified and global dynamics are completely determined by $R_{0}$. It shows that $R_{0}$ is a global threshold parameter in the sense that if $R_{0}<1$, the coopetition free equilibrium is globally stable and the market share of coopetition enterprises tends to zero, whereas if $R_{0}>1$, there is a unique coopetition equilibrium which is globally attractive with some conditions, and thus the market share of coopetition enterprises tends to a steady state value. By some sensitivity analysis of $R_{0}$ on parameters, we conclude that the size of the coopetition threshold $R_{0}$ and coopetition equilibrium depended on the cooperation competitiveness of coopetition enterprises.
\end{abstract}

\section{Introduction}

Coopetition (cooperation and competition) was put forward by Nalebuff and Brandenburger for the first time in 1996, and they discussed the importance of coopetition in business by using game theory as a theoretical frame [1]. In the same year, Bengtsson and Kock also called the phenomenon coopetition which contains competition and cooperation [2]. Coopetitive relationships are complex as they consist of two diametrically different types of logic interaction. Actors involved in coopetition are involved in a relationship that on the one hand consists of hostility due to conflicting interests and on the other hand consists of friendliness due to common interests. These two types of logic of interaction are in conflict with each other and must be separated in a proper way to make a coopetitive relationship possible. In 2000, Bengtsson and Kock studied the coopetition of corporate network [3]. The coopetition theory of Deutsch divides the target of interest subjects into cooperation, competition and independence; the relationship of the target partners affects their interaction results and then directly affects their action strategies [4]. Hausken introduced competition between groups that may induce cooperation to emerge in defection games despite considerable cost of cooperation [5]. Loebbecke et al. studied knowledge transfer and distribution which are based on coopetition [6].

With the development of the information, communication technology, networks, and virtual organizations, the coopetition phenomenon has appeared between enterprises. Resource heterogeneity determines that the supply chain of alliance partner enterprises is a symbiotic relationship with coopetition, that is, the coopetition relationships of the enterprise dominant in the supply chain network. Zhuo et al. [7] studied the supply chain alliance partner enterprise coopetition relations based on Volterra model. In their model, they considered the alliance which contains two enterprises. The following system (1) is the main model:

$$
\begin{aligned}
& \frac{d x_{1}}{d t}=r_{1} x_{1}\left(1-\frac{x_{1}}{N_{1}}\right)+\frac{\delta_{2} r_{1} x_{1} x_{2}}{N_{2}}-\frac{\lambda_{2} r_{1} x_{1} x_{2}}{N_{2}}, \\
& \frac{d x_{2}}{d t}=r_{2} x_{2}\left(1-\frac{x_{2}}{N_{2}}\right)+\frac{\delta_{1} r_{2} x_{1} x_{2}}{N_{1}}-\frac{\lambda_{1} r_{2} x_{1} x_{2}}{N_{1}},
\end{aligned}
$$

where $x_{i}$ is the production value of enterprise $i ; N_{i}$ is the limit production value of enterprise $i ; r_{i}$ is the natural growth rate of enterprise $i . \delta_{1}$ represents the contribution rate from enterprise 1 to enterprise 2 , and $\delta_{2}$ describes the contribution rate from enterprise 2 to enterprise $1 . \lambda_{1}$ represents 


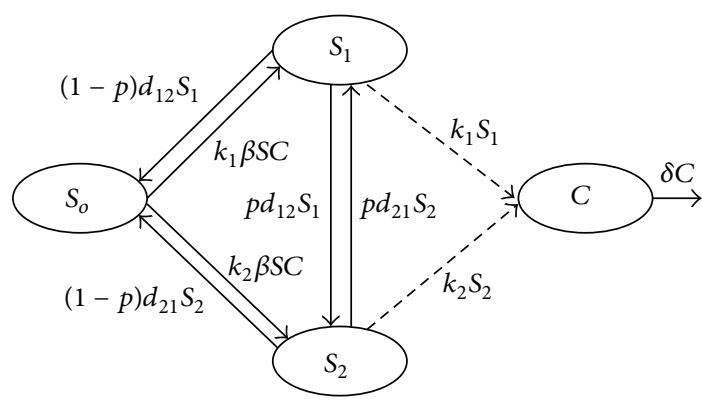

FIGURE 1: Coopetition diagram of two enterprises.

the competition rate from enterprise 1 to enterprise 2 , and $\lambda_{2}$ describes the competition rate from enterprise 2 to enterprise 1. In this model, they only considered the change of production value of enterprise about cooperation and competition and do not include the direction in which the production value has gone. Based on previous work, in this paper, we consider a deterministic model of two coopetition enterprises and other enterprises and study the change direction of the market share with coopetition strategy of these two coopetition enterprises.

The paper is organized as follows. In Section 2, we present and interpret the dynamical model that describes the market share of two coopetition enterprises and other enterprises, give the coopetition threshold of this model and the uniqueness of positive coopetition equilibrium when the coopetition threshold is larger than 1 , and prove the stability of the coopetition equilibrium. And in Section 3, some numerical simulations are showed to illustrate the effectiveness of the proposed result. Section 4 gives a brief discussion about main results.

\section{Mathematical Modeling and Analysis}

2.1. Model Formulation. In our model, we classify the market quantity of all enterprises into three compartments: $S_{1}(t)$ describes the market share of the coopetition enterprise 1, $S_{2}(t)$ denotes the market share of the coopetition enterprise 2, and $S_{o}(t)$ represents the market share of other enterprises at time $t$. Let $C(t)$ denote the density of coopetition awareness programs between two enterprises at time $t$. There are some assumptions about this dynamical model. (i) It is assumed that the market quantity of all enterprises is kept constant. (ii) The increase and decrease of the market share of these two coopetition enterprises only depended on the cooperation and competition between these two enterprises. (iii) The growth rate of density of coopetition awareness programs is assumed to be proportional to the market share of the coopetition enterprise 1 and enterprise 2. There are also some other assumptions about this dynamical model in the flowchart. More details can be found in Figure 1.

For the market share of coopetition enterprise 1 compartment $S_{1}(t)$, the input of compartment $S_{1}(t)$ includes $k_{1} \beta S_{o} C$ and $p d_{21} S_{2} \cdot k_{1} \beta S_{o} C$ denotes the market share from compartment $S_{o}(t)$ to compartment $S_{1}(t)$ through the cooperation between enterprise 1 and enterprise 2 , and $p d_{21} S_{2}$ represents the market share from compartment $S_{2}(t)$ to compartment
$S_{1}(t)$ through the competition between enterprise 1 and enterprise 2. Due to the competition between enterprise 1 and enterprise 2, the output of $S_{1}(t)$ is $d_{12} S_{1}$. So the change of $S_{1}(t)$ is as follows:

$$
\frac{d S_{1}}{d t}=k_{1} \beta S_{o} C-d_{12} S_{1}+p d_{21} S_{2} .
$$

In the same way, we can obtain the change over time in the size of the compartment $S_{2}(t)$, which is as follows:

$$
\frac{d S_{2}}{d t}=k_{2} \beta S_{o} C-d_{21} S_{2}+p d_{12} S_{1} .
$$

For the market share of other enterprises compartment $S_{o}(t)$, the output of compartment $S_{o}(t)$ includes $k_{1} \beta S_{o} C$ and $k_{2} \beta S_{o} C$, and the input of compartment $S_{o}(t)$ includes (1 p) $d_{12} S_{1}$ and $(1-p) d_{21} S_{2}$. So the change over time in the size of the compartment $S_{o}(t)$ is as follows:

$$
\frac{d S_{o}}{d t}=(1-p)\left(d_{12} S_{1}+d_{21} S_{2}\right)-\left(k_{1}+k_{2}\right) \beta S_{o} C .
$$

For the density of coopetition awareness programs compartment $C(t)$, the input of the compartment $C(t)$ contains $k_{1} S_{1}+k_{2} S_{2}$, which is the density of coopetition awareness programs discharged by the coopetition enterprises 1 and 2. The output of the compartment $C(t)$ is the depletion of coopetition awareness programs, which is $\delta C$. So the change over time in the size of the compartment $C(t)$ is as follows:

$$
\frac{d C}{d t}=k_{1} S_{1}+k_{2} S_{2}-\delta C .
$$

So the mathematical model is described as the following ordinary differential equations:

$$
\begin{gathered}
\frac{d S_{o}}{d t}=(1-p)\left(d_{12} S_{1}+d_{21} S_{2}\right)-\left(k_{1}+k_{2}\right) \beta S_{o} C, \\
\frac{d S_{1}}{d t}=k_{1} \beta S_{o} C-d_{12} S_{1}+p d_{21} S_{2}, \\
\frac{d S_{2}}{d t}=k_{2} \beta S_{o} C-d_{21} S_{2}+p d_{12} S_{1}, \\
\frac{d C}{d t}=k_{1} S_{1}+k_{2} S_{2}-\delta C,
\end{gathered}
$$

where

$$
S_{o}(t)+S_{1}(t)+S_{2}(t)=1 .
$$

All parameters are assumed to be nonnegative in system (6). $k_{1}$ and $k_{2}$ represent the rate with which cooperation awareness programs are being implemented from enterprises 1 and 2, respectively. $\delta$ denotes the depletion rate of coopetition awareness programs. $d_{21}$ represents the competition awareness programs rate from enterprise 1 to enterprise 2 , and $d_{12}$ represents the competition awareness programs rate from enterprise 2 to enterprise 1. $p(0<p<1)$ is the proportion of the market share from enterprise 1 to enterprise 2 or from enterprise 2 to enterprise 1 due to the competition between 
enterprise 1 and enterprise 2 , and $\beta$ is the transmission rate of enterprise cooperation.

For system (6), if there is no coopetition, system (6) will become the following system:

$$
\frac{d S_{o}}{d t}=0, \quad \frac{d S_{1}}{d t}=0, \quad \frac{d S_{2}}{d t}=0, \quad \frac{d C}{d t}=0 .
$$

It has an equilibrium $P_{0}=\left(S_{o}(0), S_{1}(0), S_{2}(0), C(0)\right)$.

The positive coopetition equilibrium $P^{*}=\left(S_{o}^{*}, S_{1}^{*}, S_{2}^{*}\right.$, $\left.C^{*}\right)$ and coopetition free equilibrium $P^{0}=\left(S_{o}^{0}, 0,0,0\right)$ of system (6) are determined by equations

$$
\begin{gathered}
(1-p)\left(d_{12} S_{1}+d_{21} S_{2}\right)-\left(k_{1}+k_{2}\right) \beta S_{o} C=0, \\
k_{1} \beta S_{o} C-d_{12} S_{1}+p d_{21} S_{2}=0, \\
k_{2} \beta S_{o} C-d_{21} S_{2}+p d_{12} S_{1}=0 \\
k_{1} S_{1}+k_{2} S_{2}-\delta C=0 .
\end{gathered}
$$

Calculating system (9), if $S_{1}=S_{2}=0$, we can obtain that $C=0$ and $S_{o}=S_{o}^{0}=S$, and system (6) has a coopetition free equilibrium $P^{0}=\left(S_{o}^{0}, 0,0,0\right)$; if $S_{1} \neq 0, S_{2} \neq 0$, we can obtain that

$$
\begin{gathered}
S_{o}^{*}=\frac{d_{12} d_{21} \delta\left(1-p^{2}\right)}{\beta\left(d_{12} k_{2}\left(k_{1} p+k_{2}\right)+d_{21} k_{1}\left(k_{1}+k_{2} p\right)\right)}, \\
C^{*}=\frac{d_{12} k_{2}\left(k_{2}+k_{1} p\right)+d_{21} k_{1}\left(k_{1}+k_{2} p\right)}{d_{12}\left(k_{2}+k_{1} p\right) \delta} S_{2}^{*}, \\
S_{1}^{*}=\frac{d_{21}\left(k_{1}+k_{2} p\right)}{d_{12}\left(k_{1} p+k_{2}\right)} S_{2}^{*},
\end{gathered}
$$

$S_{2}^{*}$

$$
\begin{aligned}
= & \frac{d_{12}\left(k_{1} p+k_{2}\right)}{d_{12}\left(k_{1} p+k_{2}\right)+d_{21}\left(k_{1}+k_{2} p\right)} \\
& \times\left(1-\frac{d_{12} d_{21} \delta\left(1-p^{2}\right)}{\beta\left(d_{12} k_{2}\left(k_{1} p+k_{2}\right)+d_{21} k_{1}\left(k_{1}+k_{2} p\right)\right)}\right) .
\end{aligned}
$$

For the positive coopetition equilibrium $P^{*}$ of system (6), we must make $S_{2}^{*}>0$, and it means that $1-d_{12} d_{21} \delta\left(1-p^{2}\right) /$ $\beta\left(d_{12} k_{2}\left(k_{1} p+k_{2}\right)+d_{21} k_{1}\left(k_{1}+k_{2} p\right)\right)>0$ and $\beta\left(d_{12} k_{2}\left(k_{1} p+\right.\right.$ $\left.\left.k_{2}\right)+d_{21} k_{1}\left(k_{1}+k_{2} p\right)\right) / d_{12} d_{21} \delta\left(1-p^{2}\right)>1$. So we can define the coopetition threshold by the following equation:

$$
R_{0}=\frac{\beta\left(d_{12} k_{2}\left(k_{1} p+k_{2}\right)+d_{21} k_{1}\left(k_{1}+k_{2} p\right)\right)}{d_{12} d_{21} \delta\left(1-p^{2}\right)} .
$$

From the above analysis, we can conclude that when $R_{0}<$ 1 , system (6) only has a coopetition free equilibrium $P^{0}=$ $\left(S_{o}^{0}, 0,0,0\right)$; when $R_{0}>1$, system (6) has a unique positive coopetition equilibrium $P^{*}=\left(S_{o}^{*}, S_{1}^{*}, S_{2}^{*}, C^{*}\right)$. Define the set

$$
\begin{aligned}
& X \\
& =\left\{\left(S_{o}, S_{1}, S_{2}, C\right) \mid S_{o}, S_{1}, S_{2} \geq 0,\right. \\
& \left.\quad 0 \leq C \leq \frac{d_{12} k_{2}\left(k_{2}+k_{1} p\right)+d_{21} k_{1}\left(k_{1}+k_{2} p\right)}{d_{12}\left(k_{2}+k_{1} p\right) \delta}\right\},
\end{aligned}
$$

which is invariant with respect to system (6).

2.2. Stability of the Coopetition Equilibrium. In this section, we will prove that the coopetition free equilibrium $P^{0}=\left(S_{o}^{0}\right.$, $0,0,0)$ is globally asymptotically stable. In order to prove global stability of the coopetition free equilibrium, the Lyapunov function will be used. The Lyapunov function is a powerful tool for the stability analysis of autonomous differential system, and it has been used for some epidemiological models with constant inflow and bilinear incidences or nonlinear incidences [8-16]. In the following, we will prove global stability of the coopetition free equilibrium by using a Lyapunov function.

Theorem 1. The coopetition free equilibrium $P^{0}$ of system (6) is globally asymptotically stable when $R_{0}<1$.

Proof. In order to investigate the asymptotic behavior of equilibrium $P^{0}=\left(S_{o}^{0}, 0,0,0\right)$ for system (6), we can reduce (6) to the following equations:

$$
\begin{aligned}
& \frac{d S_{1}}{d t}=k_{1} \beta S_{o} C-d_{12} S_{1}+p d_{21} S_{2}, \\
& \frac{d S_{2}}{d t}=k_{2} \beta S_{o} C-d_{21} S_{2}+p d_{12} S_{1}, \\
& \frac{d C}{d t}=k_{1} S_{1}+k_{2} S_{2}-\delta C .
\end{aligned}
$$

For the coopetition free equilibrium $P^{0}$, we define the following Lyapunov function:

$$
L_{1}=m S_{1}+n S_{2}+C \text {. }
$$

Then the derivative of $L_{1}$ along solutions of system (13) is

$$
\begin{aligned}
\frac{d L_{1}}{d t}= & m S_{1}^{\prime}+n S_{2}^{\prime}+C^{\prime} \\
= & m\left(k_{1} \beta S_{o} C-d_{12} S_{1}+p d_{21} S_{2}\right) \\
& +n\left(k_{2} \beta S_{o} C-d_{21} S_{2}+p d_{12} S_{1}\right) \\
& +k_{1} S_{1}+k_{2} S_{2}-\delta C=A+B
\end{aligned}
$$

where

$$
\begin{gathered}
A=m k_{1} \beta S_{o} C+n k_{2} \beta S_{o} C-\delta C, \\
B=m\left(-d_{12} S_{1}+p d_{21} S_{2}\right) \\
+n\left(-d_{21} S_{2}+p d_{12} S_{1}\right)+k_{1} S_{1}+k_{2} S_{2} .
\end{gathered}
$$

Considering the following equations

$$
\begin{gathered}
-m d_{12} S_{1}+n p d_{12} S_{1}+k_{1} S_{1}=0, \\
m p d_{21} S_{2}-n d_{21} S_{2} k_{2} S_{2}=0,
\end{gathered}
$$


we have

$$
\begin{aligned}
& m=\frac{d_{12} k_{2} p+d_{21} k_{1}}{d_{12} d_{21}\left(1-p^{2}\right)}, \\
& n=\frac{d_{12} k_{2}+d_{21} k_{1} p}{d_{12} d_{21}\left(1-p^{2}\right)} .
\end{aligned}
$$

Letting (18) generate into (15), we can obtain that

$$
\begin{aligned}
& \frac{d L_{1}}{d t} \\
&=A+B \\
&=\left(\frac{d_{12} k_{2} p+d_{21} k_{1}}{d_{12} d_{21}\left(1-p^{2}\right)} k_{1}+\frac{d_{12} k_{2}+d_{21} k_{1} p}{d_{12} d_{21}\left(1-p^{2}\right)} k_{2}\right) \\
& \quad \times \beta S_{0} C-\delta C \\
& \leq\left(R_{0}-1\right) \delta C .
\end{aligned}
$$

Therefore, when $R_{0}<1, d L_{1} / d t<0$, and the equality $d L_{1} / d t=0$ holds if and only if $R_{0}=1$. Thus the coopetition free equilibrium $P^{0}$ is globally asymptotically stable in $X$ by LaSalle's invariance principle [17]. This completes the proof.

Next, we will show that when $R_{0}>1$, the unique positive coopetition equilibrium $P^{*}=\left(S_{o}^{*}, S_{1}^{*}, S_{2}^{*}, C^{*}\right)$ of system (6) is globally attractive.

For system (6), the first equation is independent of the last three equations. And as for $S_{o}(t)+S_{1}(t)+S_{1}(t)=1$, system (6) has the following limiting system:

$$
\begin{aligned}
& \frac{d S_{1}}{d t}=\left(1-S_{1}-S_{2}\right) k_{1} \beta C-d_{12} S_{1}+p d_{21} S_{2}, \\
& \frac{d S_{2}}{d t}=\left(1-S_{1}-S_{2}\right) k_{2} \beta C-d_{21} S_{2}+p d_{12} S_{1}, \\
& \frac{d C}{d t}=k_{1} S_{1}+k_{2} S_{2}-\delta C .
\end{aligned}
$$

For system (20), we define the vector $\bar{x}=\left(S_{1}, S_{2}, C\right)$.

Theorem 2. When $R_{0}>1, p d_{21} \geq \max \{C(t)\} k_{1} \beta$, and $p d_{12} \geq$ $\max \{C(t)\} k_{2} \beta$, the positive coopetition equilibrium $E^{*}=\left(S_{1}^{*}\right.$, $\left.S_{2}^{*}, C^{*}\right)$ of system (20) is globally asymptotically stable with respect to $\bar{x}(0) \in X$.

Proof. We will use the theory of cooperate system to prove the global stability; therefore, we only need to verify the assumption in Corollary 3.2 in [18] for system (20).

Let $\bar{f}: X \rightarrow X$ be defined by the right-hand side of system $(20), \bar{f}=\left(f_{1}, f_{2}, f_{3}\right)$. Clearly $\bar{f}$ is continuously differentiable, $\bar{f}(0)=0, \bar{f}(\bar{x}) \geq 0$, and $D \bar{f}(\bar{x})$ is Irreducible for all $\bar{x} \in X$. Calculating the jacobian matrix of system (20) at the unique positive coopetition equilibrium $E^{*}=\left(S_{1}^{*}, S_{2}^{*}, C^{*}\right)$,

$$
\begin{aligned}
& D \bar{f}\left(E^{*}\right) \\
& =\left(\begin{array}{ccc}
-d_{12}-k_{1} \beta C^{*} & p d_{21}-k_{1} \beta C^{*} & k_{1} \beta\left(1-S_{1}^{*}-S_{2}^{*}\right) \\
p d_{12}-k_{2} \beta C^{*} & -d_{21}-k_{2} \beta C^{*} & k_{1} \beta\left(1-S_{1}^{*}-S_{2}^{*}\right) \\
k_{1} & k_{2} & -\delta
\end{array}\right) .
\end{aligned}
$$

Because $p d_{21} \geq \max \{C(t)\} k_{1} \beta$ and $p d_{12} \geq \max \{C(t)\} k_{2} \beta, \bar{f}$ is cooperative.

Note that, for $\forall \alpha \in(0,1)$ and $\bar{x}>0$,

$$
\begin{aligned}
& f_{1}(\alpha \bar{x}) \\
& =\alpha\left[\left(1-\alpha S_{1}-\alpha S_{2}\right) k_{1} \beta C-d_{12} S_{1}+p d_{21} S_{2}\right] \\
& \geq \alpha\left[\left(1-S_{1}-S_{2}\right) k_{1} \beta C-d_{12} S_{1}+p d_{21} S_{2}\right] \\
& =\alpha f_{1}(\bar{x}) .
\end{aligned}
$$

In a similar way, we can obtain that

$$
f_{2}(\alpha \bar{x}) \geq \alpha f_{2}(\bar{x}), \quad f_{3}(\alpha \bar{x})=\alpha f_{3}(\bar{x}) .
$$

Thus $\bar{f}(\alpha \bar{x}) \geq \alpha \bar{f}(\bar{x})$, which is sublinear on $X$. By Lemma 2 and Corollary 3.2 in [18], we can conclude that the positive coopetition equilibrium $E^{*}=\left(S_{1}^{*}, S_{2}^{*}, C^{*}\right)$ of system (20) is globally asymptotically stable with respect to $\bar{x}(0) \in X$.

Next, by a similar proof to that of Theorem 3.1 in [19], we will prove the following theorem.

Theorem 3. When $R_{0}>1$, the unique positive coopetition equilibrium $P^{*}=\left(S_{o}^{*}, S_{1}^{*}, S_{2}^{*}, C^{*}\right)$ of system (6) is globally attractive with respect to $\left(S_{o}(0), \bar{x}(0)\right) \in X$.

Proof. Let $\Phi(t): R_{+}^{4} \rightarrow R_{+}^{4}$ be the solution semiflow of system (6), and let $\omega$ be omega limit set of $\Phi\left(S_{o}(0), \bar{x}(0)\right)$, $\left(S_{o}(0), \bar{x}(0)\right) \in X$. By Lemmas 1 and 1.2.1 in [20], $\omega$ is an internal chain transitive set for $\Phi(t)$. Obviously, for system (6), there are only two equilibria $P^{0}$ and $P^{*}$ when $R_{0}>1$. By Theorems 1 and 3, it is not difficult to verify that $\Phi(t)$ satisfies the condition of Theorem 1.2.2 in [20]; thus, $\omega$ should be either $P^{0}$ or $P^{*}$.

Next, we prove that $\omega=\left\{P^{*}\right\}$. If this were not true; then, $\omega=\left\{P^{0}\right\}$, then we should prove $\lim _{t \rightarrow \infty} \sup S_{o}=1$, $\lim _{t \rightarrow \infty} \sup S_{1}=0, \lim _{t \rightarrow \infty} \sup S_{2}=0$, and $\lim _{t \rightarrow \infty} \sup C=$ 0 . Let

$$
M=\left(\begin{array}{ccc}
-d_{12} & p d_{21} & k_{1} \beta \\
p d_{12} & -d_{21} & k_{1} \beta \\
k_{1} & k_{2} & -\delta
\end{array}\right)
$$

Obviously, $M$ is irreducible and has nonnegative off-diagonal elements. Define $s(M)=\max \{\operatorname{Re} \lambda: \lambda$ as an eigenvalue of $M\}$, so $s(M)$ is a simple eigenvalue of $M$ with a positive eigenvector [21]. By Theorem 2 of van den Driessche and Watmough [22], there hold two equivalences:

$$
\begin{aligned}
& \mathscr{R}_{0}>1 \Longleftrightarrow s(M)>0, \\
& \mathscr{R}_{0}<1 \Longleftrightarrow s(M)<0 .
\end{aligned}
$$

Since $s(M)>0$, we can choose a small $\varepsilon>0$ such that $s\left(M_{2}\right)>0,\left(M_{2}=M+\varepsilon M_{1}\right)$, where

$$
M_{1}=\left(\begin{array}{ccc}
0 & 0 & k_{1} \beta \\
0 & 0 & k_{1} \beta \\
0 & 0 & 0
\end{array}\right) .
$$


It follows that there exists a $t_{0}$ such that $1-S_{1}-S_{2}>1-\varepsilon$, for $t>t_{0}$. Thus, we have

$$
\begin{aligned}
& \frac{d S_{1}}{d t}>(1-\varepsilon) k_{1} \beta C-d_{12} S_{1}+p d_{21} S_{2} \\
& \frac{d S_{2}}{d t}>(1-\varepsilon) k_{2} \beta C-d_{21} S_{2}+p d_{12} S_{1} \\
& \frac{d C}{d t}=k_{1} S_{1}+k_{2} S_{2}-\delta C .
\end{aligned}
$$

Consider the following system:

$$
\begin{aligned}
& \frac{d S_{1}^{\prime}}{d t}=(1-\varepsilon) k_{1} \beta C^{\prime}-d_{12} S_{1}^{\prime}+p d_{21} S_{2}^{\prime}, \\
& \frac{d S_{2}^{\prime}}{d t}=(1-\varepsilon) k_{2} \beta C^{\prime}-d_{21} S_{2}^{\prime}+p d_{12} S_{1}^{\prime}, \\
& \frac{d C^{\prime}}{d t}=k_{1} S_{1}^{\prime}+k_{2} S_{2}^{\prime}-\delta C^{\prime} .
\end{aligned}
$$

Since the matrix $M_{2}$ has positive eigenvalue $s\left(M_{2}\right)$ with a positive eigenvector, it is easy to see that $\left(S_{1}^{\prime}(t), S_{2}^{\prime}(t), C^{\prime}(t)\right) \rightarrow$ $(\infty, \infty, \infty), t \rightarrow \infty$. Using the comparison principle of Smith and Waltman [21], we also know that $\left(S_{1}(t), S_{2}(t)\right.$, $C(t)) \rightarrow(\infty, \infty, \infty), t \rightarrow \infty$, which leads to a contradiction. Consequently the unique positive coopetition equilib$\operatorname{rium} P^{*}=\left(S_{o}^{*}, S_{1}^{*}, S_{2}^{*}, C^{*}\right)$ is globally attractive.

So far all our analyses are focused on the mathematical models and their dynamic behavior, such as the coopetition threshold, the uniqueness of positive coopetition equilibrium, the global stability of the coopetition free equilibrium, and the global attraction of the positive coopetition equilibrium. We want to seek out how the coopetition strategy influences the market share of the coopetition enterprises, so in the next section, we will present some numerical simulations about the global stability of the coopetition equilibrium and give some sensitivity analysis of the coopetition threshold $R_{0}$ on parameters.

\section{Numerical Simulations}

In this coopetition model, the coopetition threshold $R_{0}$ is calculated and shown to be a threshold for the dynamics of the coopetition model. The main purpose is to let the market share of the two enterprises coexist by making the threshold $R_{0}$ to be more than 1 , so we must know how the coopetition threshold depends on the model parameter values. In the following result, we will show that the coopetition threshold $R_{0}$ is a global threshold parameter for the extinction and persistence of the coopetition.

Taking $\beta=0.025, p=0.4, d_{12}=0.7, d_{21}=0.6$, and $\delta=3$ and using MATLAB ODE solver, we run numerical simulations for the case with $R_{0}<1$ (see Figure 2) and the case with $R_{0}>1$ (see Figure 3 ) to demonstrate the conclusions in Theorems 1 and 3 .

From Figure 2, we can see that the trajectory of system (6) will tend to the coopetition free equilibrium with different

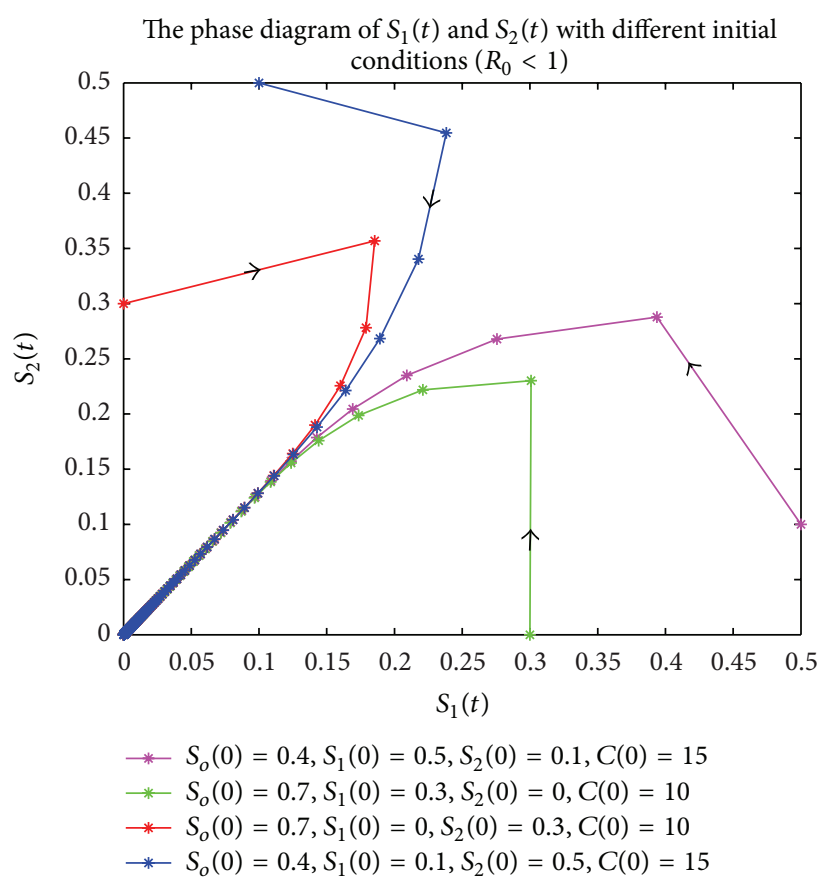

Figure 2: The phase diagram of $S_{1}(t)$ and $S_{2}(t)$ with $k_{1}=4$ and $k_{2}=5$. This gives $R_{0} \approx 0.8858<1$ and the coopetition makes the market share of the enterprise not coexist.

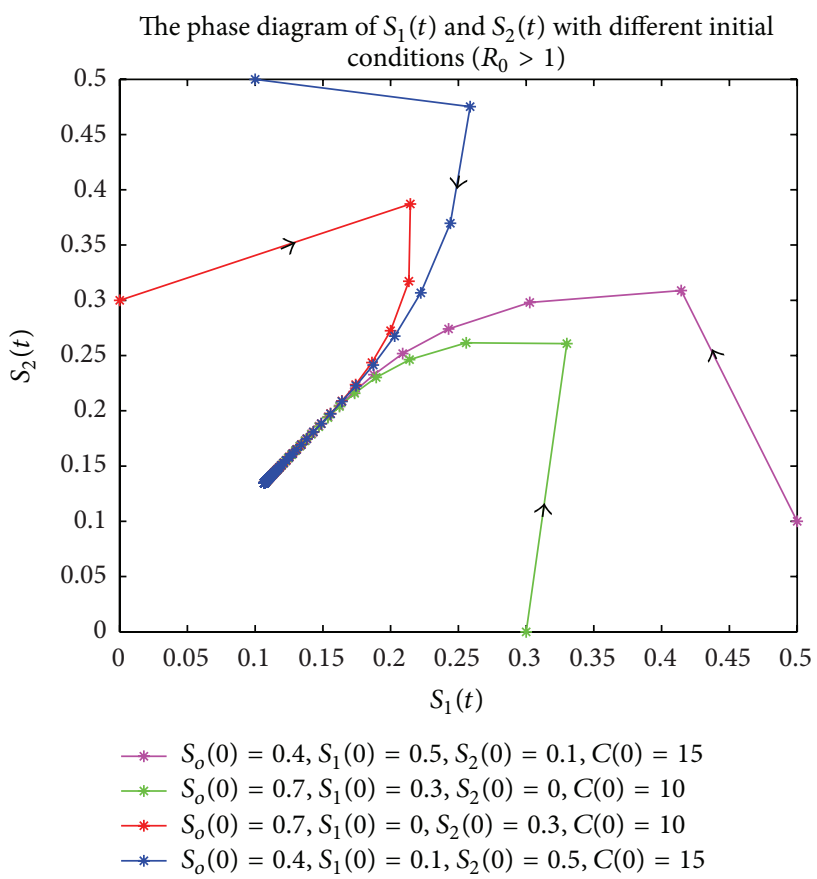

FIgURE 3: The phase diagram of $S_{1}(t)$ and $S_{2}(t)$ with $k_{1}=5$ and $k_{2}=6$. This gives $R_{0} \approx 1.3180<1$ and the coopetition makes the market share of the enterprise coexist.

initial conditions when the coopetition threshold $R_{0}$ is less than 1 , so it is concluded that the coopetition free equilibrium is stable when the coopetition threshold $R_{0}<1$. From Figure 3, we can also conclude that the coopetition equilibrium is stable when the coopetition threshold $R_{0}$ is more than 1 . For the coopetition enterprises, the main purpose is 


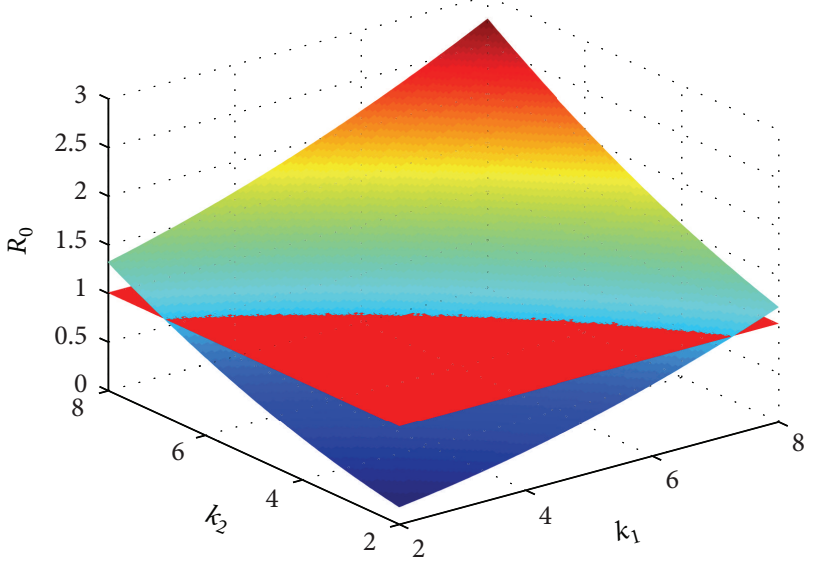

(a)

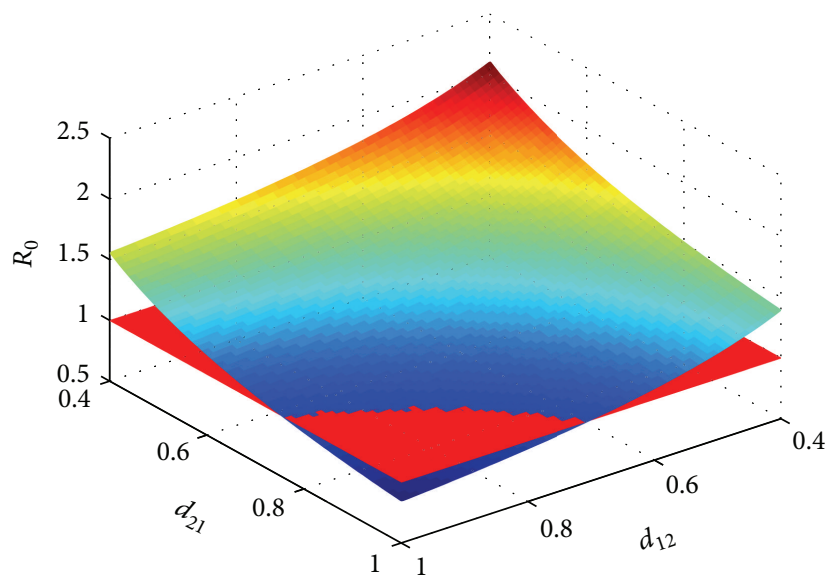

(b)

FIgURE 4: (a) The coopetition threshold $R_{0}$ in terms of $k_{1}, k_{2}$. (b) The coopetition threshold $R_{0}$ in terms of $d_{12}, d_{21}$.

keeping mutual benefit equilibrium in the cooperation and competition. In this situation, we must make the coopetition threshold $R_{0}$ more than 1 .

From the expression of the coopetition threshold $R_{0}$ of system (6), it is easy to see that all parameter values are directly or indirectly contained in $R_{0}$. So some sensitivity analyses of the coopetition threshold $R_{0}$ about parameters are given in the following section.

Figure 4(a) shows that increasing $k_{1}$ or $k_{2}$ can increase the coopetition threshold $R_{0}$. However, in Figure 4(b), an increase in $d_{12}$ or $d_{21}$ will decrease the coopetition threshold $R_{0}$. When the coopetition awareness programs rate $\left(k_{1}, k_{2}\right)$ or the competition awareness programs rate $\left(d_{12}, d_{21}\right)$ reaches a certain level, it will make the coopetition threshold $R_{0}$ more than 1 , and then the coopetition enterprises will keep mutual benefit equilibrium in the cooperation and competition.

When the coopetition threshold $R_{0}$ is more than 1 , we want to know the market share of these two coopetition enterprises at the equilibrium state. From the expression of the coopetition equilibrium $P^{*}$, we also know that $S_{1}^{*}$ and $S_{2}^{*}$ are increasing with respect to $k_{1}$ or $k_{2}$, and an increase in $d_{12}$ or $d_{21}$ will decrease $S_{1}^{*}$ and $S_{2}^{*}$. In the same way, if the coopetition enterprises want to have enough market share, the coopetition awareness programs rate $\left(k_{1}, k_{2}\right)$ and the competition awareness programs rate $\left(d_{12}, d_{21}\right)$ must also reach a certain level.

\section{Conclusion and Discussion}

Coopetition is different competition and cooperation, which contains two components of competition and cooperation by using game theory. In network organizations, enterprises often cooperate with other enterprises in order to compete more effectively. In order to seize the opportunity from cooperation, enterprises will also seek attractive partners with a competitive attitude. In fact, cooperation and competition are a relative force, which gives the positive and negative effect in the market [7]. So in this paper, we propose a deterministic model of two coopetition enterprises and other enterprises to describe the change of market share of these two coopetition enterprises. It is found that the model has the coopetition threshold $R_{0}$ and two nonnegative equilibria, the coopetition free equilibrium and the coopetition equilibrium. The coopetition free equilibrium exists without any condition whereas the coopetition equilibrium exists provided $R_{0}>1$. Through the analysis of the model, it has been found that the global asymptotic behavior of system (6) is completely determined by the size of the coopetition threshold $R_{0}$; that is, the coopetition free equilibrium is globally asymptotically stable if $R_{0}<1$ while a coopetition equilibrium exists uniquely and is globally attractive if $R_{0}>1$.

By some sensitivity analysis of the coopetition threshold $R_{0}$ on parameters, we find that increasing the coopetition awareness programs rate $\left(k_{1}, k_{2}\right)$ or decreasing the competition awareness programs rate $\left(d_{12}, d_{21}\right)$ can increase the coopetition threshold $R_{0}$. From the expression of the coopetition equilibrium $P^{*}$, we also know that $S_{1}^{*}$ and $S_{2}^{*}$ are increasing with respect to $k_{1}$ or $k_{2}$, and an increase in $d_{12}$ or $d_{21}$ will decrease $S_{1}^{*}$ and $S_{2}^{*}$. So we can conclude that the size of the coopetition equilibrium depended on the cooperation competitiveness of these two coopetition enterprises. This conclusion is well explained that there is a symbiotic relationship between enterprises (which contains both cooperation and competition, and both are paid and rewarding) and the coopetition enterprise can achieve mutual benefit equilibrium in the cooperation and competition.

The cooperative competition relationship between enterprises is involved in many aspects. In this paper, we only study the basic rule of coopetition between enterprises, and there also exist some assumptions on this dynamical model. We do not consider the situation without these assumptions, and the information sharing and blockade of coopetition enterprise can not be also taken into account in this model. So we need to continue research in the future. Furthermore, many researches have been performed to study spatial dynamics [23] which can be used to model the relationships between enterprises. 


\section{Conflict of Interests}

The author declares that she has no conflict of interests.

\section{Acknowledgments}

This work was supported by the Ministry of Education of Humanities and Social Science Research Funds for Young (11YJC630090 and 10YJC630114) and the Shanxi Soft Science Research Funds (2011041034-01 and 2012041009-03).

\section{References}

[1] B. Nalebuff and A. Brandenburger, Co-Opetition, Harvard Business Press, Cambridge, Mass, USA, 1996.

[2] M. Bengtsson and S. Kock, "Cooperation and competition among horizontal actors in business networks," in Proceedings of the 6th Workshop on Interorganizational Research, pp. 23-25, Augus 1996.

[3] M. Bengtsson and S. Kock, "Coopetition in business networksto cooperate and compete simultaneously," Industrial Marketing Management, vol. 29, no. 5, pp. 411-426, 2000.

[4] M. Deutsch, Over Fifty Years of Conict Research, pp. 46-77, Oxford University Press, New York, NY, USA, 1980.

[5] K. Hausken, "Cooperation and between-group competition," Journal of Economic Behavior and Organization, vol. 42, no. 3, pp. $417-425,2000$

[6] C. Loebbecke, P. C. van Fenema, P. Powell et al., "Knowledge transfer under co-opetition," in Information Systems: Current Issues and Future Changes, pp. 215-229, American Management System, 1997.

[7] X. Z. Zhuo, X. Wang, and Z. F. Wang, "The research of supply chain alliance partner enterprise co-opetition relations based on volterra model," Journal of Industrial Engineering, vol. 24, pp. 134-137, 2010.

[8] J. Li, Y. Yang, and Y. Zhou, "Global stability of an epidemic model with latent stage and vaccination," Nonlinear Analysis: Real World Applications, vol. 12, no. 4, pp. 2163-2173, 2011.

[9] H. Guo, M. Y. Li, and Z. Shuai, "Global stability of the endemic equilibrium of multigroup SIR epidemic models," Canadian Applied Mathematics Quarterly, vol. 14, pp. 259-284, 2006.

[10] H. Guo, M. Y. Li, and Z. Shuai, "A graph-theoretic approach to the method of global Lyapunov functions," Proceedings of the American Mathematical Society, vol. 136, no. 8, pp. 2793-2802, 2008.

[11] A. Korobeinikov, "Global properties of SIR and SEIR epidemic models with multiple parallel infectious stages," Bulletin of Mathematical Biology, vol. 71, no. 1, pp. 75-83, 2009.

[12] A. Korobeinikov and P. K. Maini, "Non-linear incidence and stability of infectious disease models," Mathematical Medicine and Biology, vol. 22, no. 2, pp. 113-128, 2005.

[13] A. Korobeinikov, "Lyapunov functions and global stability for SIR and SIRS epidemiological models with non-linear transmission," Bulletin of Mathematical Biology, vol. 68, no. 3, pp. 615-626, 2006.

[14] A. Korobeinikov, "Global properties of infectious disease models with nonlinear incidence," Bulletin of Mathematical Biology, vol. 69, no. 6, pp. 1871-1886, 2007.

[15] Z. Yuan and L. Wang, "Global stability of epidemiological models with group mixing and nonlinear incidence rates,"
Nonlinear Analysis: Real World Applications, vol. 11, no. 2, pp. 995-1004, 2010.

[16] R. Sun and J. Shi, "Global stability of multigroup epidemic model with group mixing and nonlinear incidence rates," Applied Mathematics and Computation, vol. 218, no. 2, pp. 280286, 2011

[17] J. P. LaSalle, The Stability of Dynamical Systems, Regional Conference Series in Applied Mathematics, SIAM, Philadelphia, Pa, USA, 1976.

[18] X. Q. Zhao and Z. J. Jing, "Global asymptotic behavior in some cooperative systems of functional differential equations," Canadian Applied Mathematics Quarterly, vol. 4, pp. 421-444, 1996.

[19] Y. Jin and W. Wang, "The effect of population dispersal on the spread of a disease," Journal of Mathematical Analysis and Applications, vol. 308, no. 1, pp. 343-364, 2005.

[20] X. Q. Zhao, Dynamical Systems in Population Biology, Springer, New York, NY, USA, 2003.

[21] H. L. Smith and P. Waltman, The Theory of the Chemostat, Cambridge University Press, Cambridge, UK, 1995.

[22] P. van den Driessche and J. Watmough, "Reproduction numbers and sub-threshold endemic equilibria for compartmental models of disease transmission," Mathematical Biosciences, vol. 180, pp. 29-48, 2002.

[23] G. Q. Sun, L. Li, and Z. K. Zhang, "Spatial dynamics of a vegetation model in an arid flat environment," Nonlinear Dynamics, vol. 73, pp. 2207-2219, 2013. 


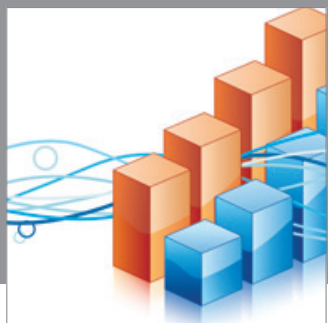

Advances in

Operations Research

mansans

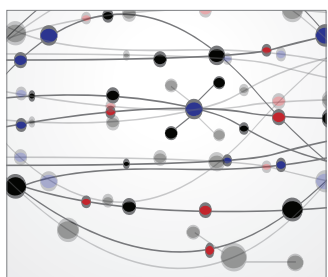

The Scientific World Journal
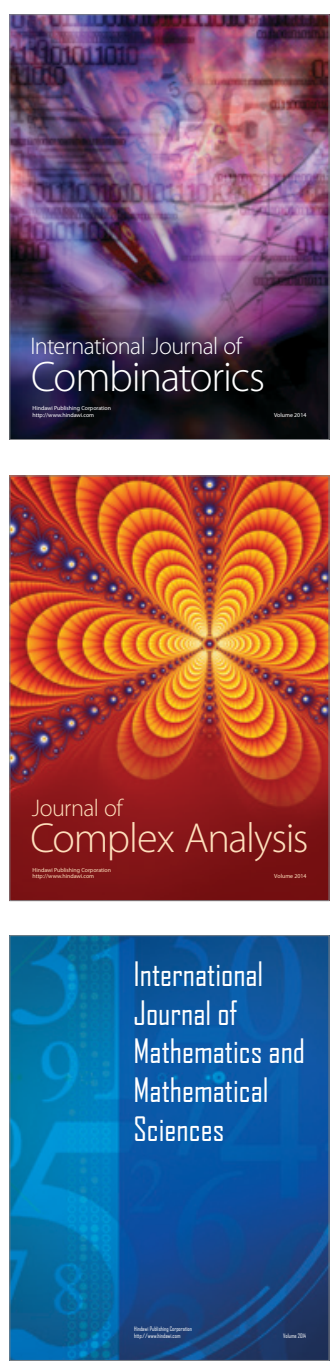
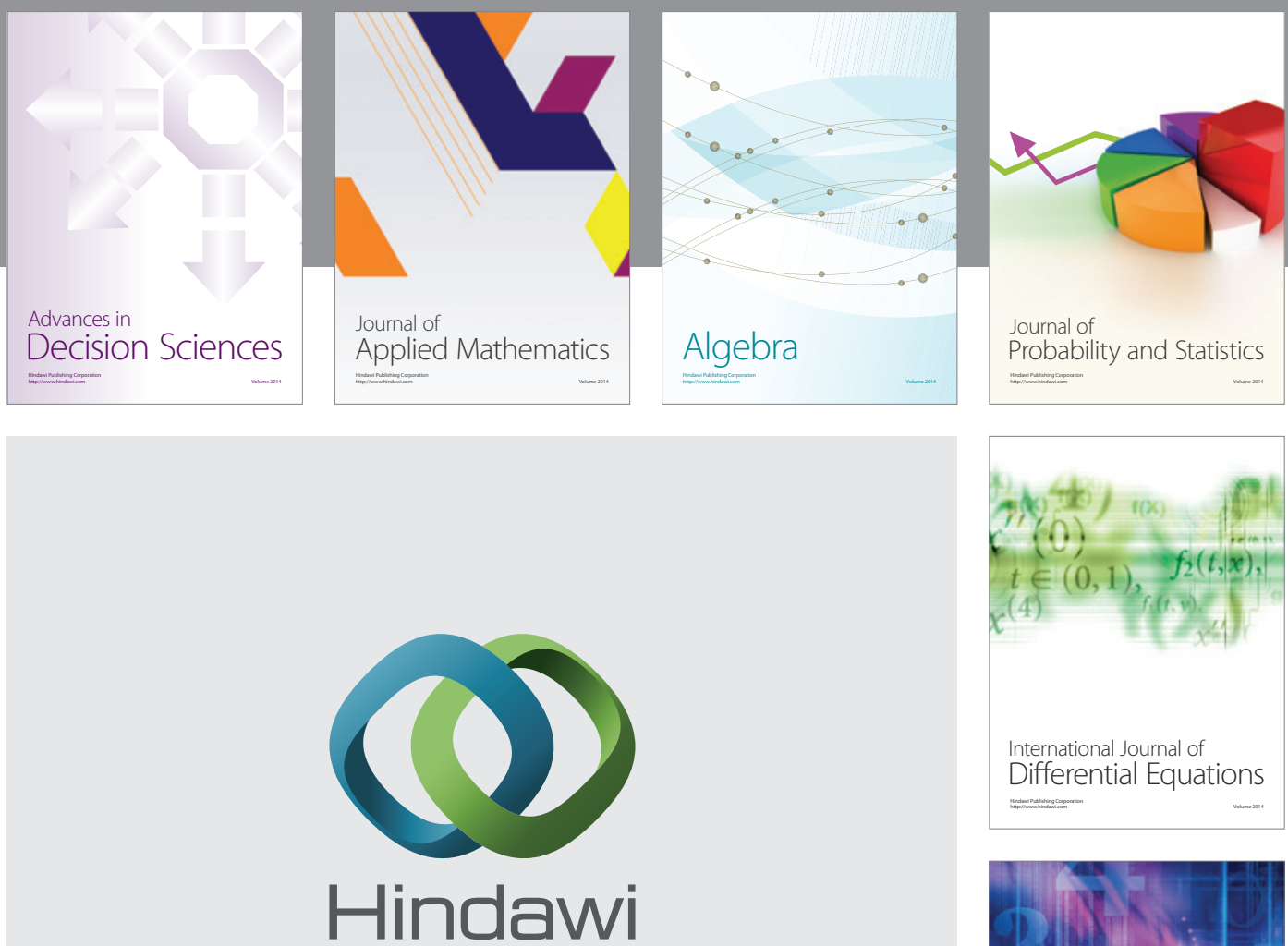

Submit your manuscripts at http://www.hindawi.com
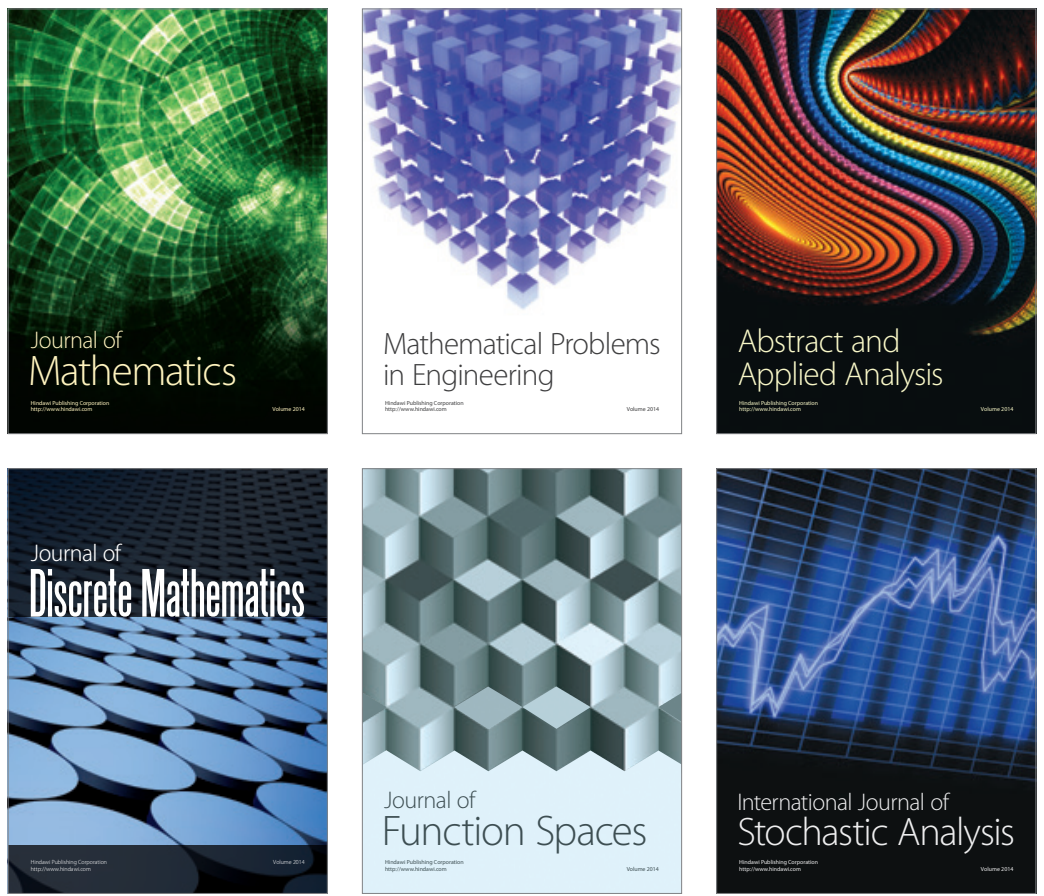

Journal of

Function Spaces

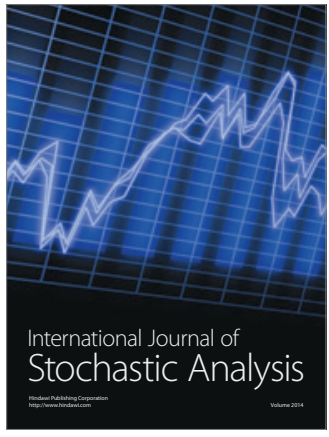

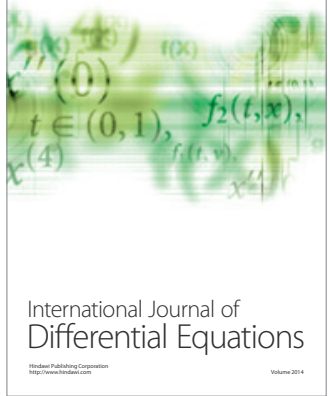
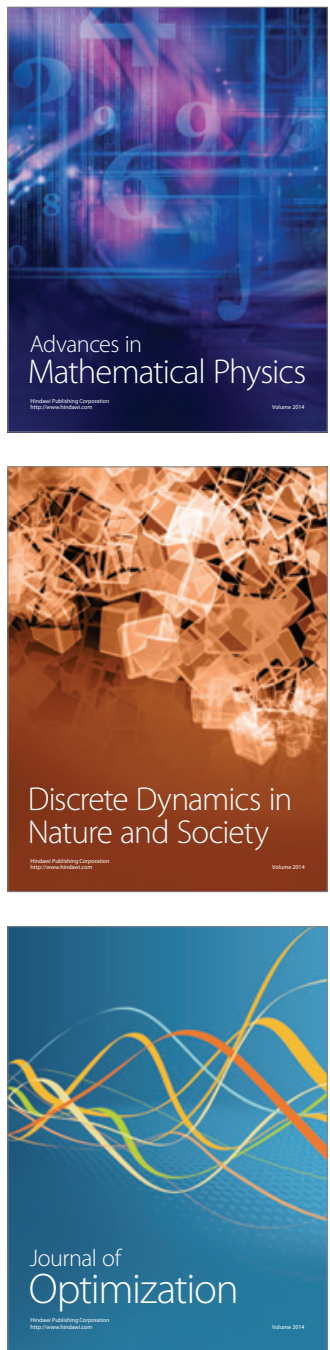